\title{
A multidisciplinary community based rehabilitation programme improved social functioning in severe traumatic brain injury
}

Sources of funding: Medical Research Council and

Department of Health.

For correspondence: Dr J Powell,

Department of

Psychology, Goldsmiths

College, London, UK

j.powell@gold.ac.uk

\begin{abstract}
Powell J, Heslin J, Greenwood R. Community based rehabilitation after severe traumatic brain injury: a randomised controlled trial. J Neurol Neurosurg Psychiatry 2002 Feb;72:193-202.
\end{abstract}

QUESTION: In patients with severe traumatic brain injury (TBI), does a multidisciplinary community based outreach rehabilitation programme improve activities of daily living, social participation, and psychological wellbeing?

A modified version of the abstract and

commentary appears in

Evidence-Based

Medicine.

Design

Randomised (allocation concealed*), blinded (outcome assessors)*, controlled trial with a mean follow up of 24.8 months.

Community outreach programme v information only in traumatic brain injury at a mean of 24.8 months follow up

\begin{tabular}{llll} 
& \multicolumn{2}{l}{ Median change scores (range) } & \multirow{2}{*}{ P valuet } \\
\cline { 2 - 3 } BICRO-39 Scores & Outreach & Information & \\
Total Score & $2.5(-1.7$ to 6.2$)$ & $0.9(-4.1$ to 6.8$)$ & $<0.05$ \\
\hline Maximum gain index & $1.6(0.2$ to 2.6$)$ & $1.0(0.0$ to 3.3$)$ & $<0.03$ \\
\hline Self organisation & $0.4(-2.8$ to 2.2$)$ & $0.1(-1.5$ to 3.1$)$ & $<0.03$ \\
\hline Psychological wellbeing & $0.6(-2.0$ to 2.6$)$ & $0.2(-1.8$ to 1.3$)$ & $<0.05$
\end{tabular}

BICRO-39=Brain Injury Community Rehabilitation Outcome-39.

†Probability levels for group comparisons (Mann-Whitney U tests)

\section{COMMENTARY}

In 1998, Chesnut et al published an evidence based analysis of TBI rehabilitation. ${ }^{1}$ They were able to draw few positive conclusions about the efficacy of rehabilitation due to the dearth of available evidence. This important study by Powell et al provides a welcome counterpoint as it supports the usefulness of ongoing community based rehabilitation for people with TBI. Particularly noteworthy is the design, one of the few randomised controlled trials related to community based rehabilitation; ${ }^{2}$ the inexpensive intervention; the similarity of the intervention to other publicly funded community based rehabilitation programmes; and that change occurred many years after TBI

There are several limitations in the study. Firstly, the 2 primary outcome measures used had substantial ceiling and floor effects (BI and 2 subscales of the BICRO-39). The use of other available measures of community integration might have avoided this problem. ${ }^{3}$ Secondly, the outreach group did not make substantive gains in terms of returning to paid employment, school, and/or childcare nor in terms of improving non-family social contact, 2 key indicators of successful community integration. It is possible, as the authors suggest, that obstacles beyond the control of therapist and/or patient are the reason for this. However, altering some of the parameters of the therapy may have a positive effect. This study contributes to the growing body of evidence suggesting that multifaceted rehabilitation approaches provide the best outcomes, ${ }^{4}$ but also illustrates that more needs to be done.

The take home message is this: functionally based rehabilitation shows promise for improving day to day life for people with severe TBI even many years after injury. Although further evidence is needed to substantiate these findings and address questions about the content, intensity, duration, and timing of rehabilitation, time since injury should not preclude referral to community based services.

Deirdre R Dawson, $\mathrm{PhD}, \mathrm{OT}(\mathrm{C})$ Kunin-Lunenfeld Applied Research Unit E University of Toronto Toronto, Ontario, Canada

1 Chesnut RM, Carney N, Maynard H, et al. Rehabilitation for traumatic brain injury. Evidence report no 2. Rockville, MD: Agency for Health Care Policy and Research, February 1999. http://www.ahrq.gov/clinic/epcsums/tbisumm.htm

2 Clark F, Azen SP, Zemke R, et al. Occupational therapy for independent-living older adults. A randomized controlled trial. JAMA 1997;278:1321-6.

3 Dikmen S, Machamer J, Miller B, et al. Functional status examination: a new instrument for assessing outcome in traumatic brain injury. J Neurotrauma 2001;18:127-40.

4 Winocur G, Palmer H, Stuss DT, et al. Cognitive rehabilitation in clinical neuropsychology. Brain Cogn 2000;42:120-3.

\section{Setting}

An urban setting of east London, UK.

\section{Patients}

110 patients, $16-65$ years of age, who sustained severe TBI 3 months to 20 years previously with no other neurological conditions. 94 patients $(85 \%$, mean age 34 y, $76 \%$ men) participated in the end of study assessment.

\section{Intervention}

54 patients were allocated to a multidisciplinary community based outreach rehabilitation programme and 56 were allocated to an information only group. Rehabilitation was highly individualised in intensity, duration, and form of treatment with patients seen in their homes or other community settings for 2-6 hours per week for an average of 27 weeks.

\section{Main outcome measures}

Scores on the Barthel Index (BI), the Brain Injury Community Rehabilitation Outcome-39 (BICRO-39), the Functional Independence/Assessment Measure (FIM+FAM), and the Hospital Anxiety and Depression Scale (HADS). An individually determined change score, the maximum gain index (MGI), was also calculated by identifying the subscale on which each patient showed the greatest improvement from intake to follow up.

\section{Main results}

Analysis was by intention to treat. On the BI, 35\% of patients in the outreach (treatment) group showed improvement compared with $20 \%$ of patients in the information group (Mann Whitney $U$ test on ranked changed scores, mean rank 53.2 v 41.6, $\mathrm{p}<0.05$ ). Median change scores on the BICRO-39 were greater for those in the outreach group than for those in the information group for the total score, the MGI, and the self organisation and psychological wellbeing subscores (table). The FIM+FAM and HADS scores showed similar improvements in both groups. However, the MGI for the FIM+FAM was greater for those in the outreach group than for those in the information group (mean rank $53.2 v 40.4, \mathrm{p}<0.03)$. Time since brain injury was not related to the magnitude of gain.

\section{Conclusion}

In severe traumatic brain injury, a multidisciplinary community based outreach rehabilitation programme improved social functioning.

*See glossary. 